\title{
From 07.00 to 22.00: A Dual-Earner Couple's Typical Day in Italy
}

\section{Old Questions and New Evidence from Social Sequence Analysis}

\author{
Ivano Bison and Alessandro Scalcon
}

\section{Introduction}

How do dual-earner couples organize their workdays and how do they (de)synchronize their daily activities? These are the questions that we address in this paper using a multichannel sequence analysis approach. Our purpose is to consider the couples' division of work-family activities in holistic terms by setting it within the context of everyday life, that is, the overall temporal pattern of combination of His and Her multiple activities. ${ }^{1}$

Our multichannel approach is based on a Lexicographic Index (Bison 2011) that seeks to overcome some optimal matching limits of sequence analysis (Bison 2009). The case-study concerns Italian dual-earner couples and uses data from the Italian Time Use Survey 2008 (Istat 2011).

We know that for dual-earner couples the risk of experiencing a certain "lack of family time" is higher than for other couples (Saraceno 2012), due to the combination and the rigidity of His and Her work constraints. The spouses of these couples face various challenges: according to their working schedules, they are required to find the right amount of time for their family-i.e. housework, childcare and other non-paid work-as well as with their family-i.e. desirable

\footnotetext{
${ }^{1}$ We immediately point out that, in this paper, we only consider heterosexual couples, because of the limitations of the Italian Time Use Survey questionnaire. Moreover, we stress that the choice of using the male pronoun before the female one is perfectly conscious: to make the reading easier, we needed to follow a single criterion and we decided to cite the spouses following the order of records in our data files, i.e. male-female.
}

I. Bison $(\varangle) \cdot$ A. Scalcon

Department of Sociology and Social Research, University of Trento, Trento, Italy

e-mail: ivano.bison@unitn.it

G. Ritschard, M. Studer (eds.), Sequence Analysis and Related Approaches,

Life Course Research and Social Policies 10,

https://doi.org/10.1007/978-3-319-95420-2_14 
and shared activities, such as free time-integrating collective needs with individual ones. In other words, the time scarcity of dual-earner couples obliges them to adopt a complementary strategy (Mansour and McKinnish 2014) in order to reconcile their multiple family needs of "production" and "consumption", while preserving their personal satisfaction with work and daily life. The two individual careers have to coexist with a third one: family life.

In this scenario, an important component of a dual-earner couple's strategy is synchronization/desynchronization. For instance, previous studies show that a certain degree of desynchronization of working schedules may be a useful solution for partners because it can promote a more equal division of housework and child care (Presser 1994; Chenu and Robinson 2002; Lesnard 2008; Naldini and Saraceno 2011). At the same time, it is recognized that a certain degree of synchronization in work commitments can encourage the partners to spend time together in other desirable activities (Hamermesh 2002; Lesnard 2008).

More generally, looking at (de)synchronizations is important because they reveal a latent behavioral pattern of different work-family specializations and suggest new explanations for the continuing persistence of gender inequalities in the division of work-family activities. The study of (de)synchronizations could enable identification of multiple equilibria (Esping-Andersen et al. 2013). According to EspingAndersen and colleagues, such study could reveal different behavioral patterns of work-family specializations-(i) egalitarian, (ii) unstable and (iii) traditionalresulting from systematic co-action by different generative mechanisms, both symbolic-cultural (e.g. Berk 1985; West and Zimmerman 1987) and economicmaterial (e.g. Becker 1964; Coverman 1985; Manser and Brown 1980).

How do we measure (de)synchronizations? There are two radically different main approaches: time budgets - the dominant approach in the time use literatureand sequence analysis.

In the former approach, we measure (de)synchronizations as the amount of time in which both the spouses have or have not done an activity at the same time or have or have not spent that time together in the same place. Thus, we obtain synchronicity ratios or percentages. However, in this way nothing is known about when the activity schedules overlap. This is a crucial limitation for two main reasons.

First, time is socially structured, and so too are social rhythms and constraints. Hence, being simultaneously at work at 10 a.m. or $10 \mathrm{p} . \mathrm{m}$. has radically different impacts on a couple's daily life. Furthermore, different timings in working schedules may have radically different impacts on daily life if combined with other time demanding features, like for instance the institutional constraints of children's schedules (e.g. school hours).

Second, take the case of a full-time shift perfectly synchronized with a part-time afternoon shift: by considering only the duration of the overlap, we will mistakenly classify it as a highly desynchronized working schedule. However, such kinds of structural desynchronization — due simply to differences in duration-should not be compared with hypothetical other kinds with the same off-scheduling amount but different and more complex organization during the day (Nock and Kingston 1984). 
According to Lesnard (2008), if we know little about how family time is daily balanced with work time for both spouses, this is mainly because we are used to adopting the too simplistic approach of the dominant time-budget perspective. To date, scholars have underestimated the importance of daily scheduling, while paying more attention to total amounts of time (Lesnard 2008). They have traditionally acquired time budget information related to different daily activities, but these should be seen in a holistic perspective that makes it possible to study the couple's days as a whole, avoiding the manipulation of time as if it were clay.

An alternative to the time-budget approach is sequence analysis (Lesnard 2008). According to Hallberg (2003), "while the traditional time allocation model typically studies the total time spent in, e.g., market work, over a day or a week, it provides little or no insight into the temporal pattern of time-use and therefore, potentially, misses a vital part of the mechanisms underlying empirical observations". A sequence analysis of time-use would evidence the routine aspects of daily life, as well as the couples' projects (Hagerstrand 1982), the performance of their complementary strategy across several daily constraints and unexpected events (Hellgren 2014). Finally, the analysis of time-use temporal patterns-instead of time budgets-seems more relevant in the study of the daily strategies and behaviors of a couple (Hallberg 2003).

We have pointed out that in order to understand the complexity of work-family balance strategies, it is necessary to study the couple's daily time-use pattern as a whole and in a more holistic way by adopting a multichannel sequence analysis approach. In the following section, we introduce the Lexicographic Index used to measure the resemblance between multinomial sequences. Section 3 sets out the data and methods. Section 4 presents the main statistical and graphical results of this study. Finally, Sect. 5 is devoted to summing up the main findings.

\section{The Lexicographic Index}

There are three main problems with current techniques used to compute the distances among sequences. One derives from the way in which similarity between two sequences is defined (Abbott and Tsay 2000; Wu 2000; Dijkstra and Taris 1995; Elzinga 2003; Bison 2009); the second is how to handle multinomial sequences (Abbott 1990); the third is how to treat a multichannel sequence as a whole (Gauthier et al. 2010).

Here we present an alternative method for computing distances among sequences. The lexicographic index (Bison 2011) is based on the sorting order of two different modes of observing events in a binary sequence. The first order is given by duration, that is the quantity of time, and is therefore based on the total number of observed events $u$ in the sequence $x$. The second order is timing, that is when this event happens, i.e. the 'places' $s_{k}(k=1, \ldots, u)$ in the sequence 
when 1 occurs. $^{2}$ For instance, we may have only three binary sequences of length 3 and $u=1$. They differ according to when the event occurred; at time $t 1, t 2$ or $t 3$. Hence, we may order these sequences [100], [010] and [001] according to the time order of events. Because the nature of the sorting order is double, the proposed index consists of two distinct parts.

The first part, $d^{\prime}(x)$, ranging from 0 to 1 , takes account of the duration and therefore the different amounts of realization $u$ recorded in the sequence:

$$
d^{\prime}(x)=u / T \text { for } u>0 \quad \text { and } \quad 0 \text { for } u=0
$$

where $T$ is the length of the sequence.

The second part, $d^{\prime \prime}(x)$, ranging from 0 to 1 , takes account of timing and therefore the different numbers of combinations displayed by the sequences with variation in the amount of time. It is

$$
d^{\prime \prime}(x)= \begin{cases}0 & \text { for } u=0 \\
\frac{\left(\begin{array}{l}
T \\
u
\end{array}\right)}{\left(\begin{array}{l}
T \\
u
\end{array}\right)+1} \frac{1+\left(\begin{array}{l}
T \\
u
\end{array}\right)-\left[\left(\begin{array}{l}
B_{u} \\
C_{u}
\end{array}\right)-\sum_{k=1}^{u}\left(\begin{array}{l}
B_{k} \\
C_{k}
\end{array}\right)-\left(\begin{array}{l}
A_{k} \\
C_{k}
\end{array}\right)\right]}{\left(\begin{array}{l}
T \\
u
\end{array}\right)} & \text { for } 0<u<T \\
1 & \text { for } u=T\end{cases}
$$

where $A_{k}$ is the exact position of $s_{k}$ in the sequence, $B_{k}$ is the last position that $s_{k}$ can occupy within the sequence, and $C_{k}$ is the first position that $s_{k}$ can occupy. For example, for sequence [0101], with $T=4$ and $u=2$, we have: for $s_{1}$ the exact place of the first 1 is $A_{1}=2$, the last position is $B_{1}=3$ and the first position is $C_{1}=1$; for $s_{2}$ the exact place of the second 1 is $A_{2}=4$, the last position is $B_{2}=4$ and the first position is $C_{2}=2$, the value of $d^{\prime \prime}([0101])$ is 0.285714 and is obtained as

$$
\frac{\frac{4 !}{2 !(4-2) !}}{\frac{4 !}{2 !(4-2) !}+1} \frac{1+\frac{4 !}{2 !(4-2) !}-\left(\frac{4 !}{2 !(4-2) !}-\left(\frac{3 !}{1 !(3-1) !}-\frac{2 !}{1 !(2-1) !}+\frac{4 !}{2 !(4-2) !}-\frac{4 !}{2 !(4-2) !}\right)\right)}{\frac{4 !}{2 !(4-2) !}} \text {. }
$$

In turn, these two indices are the coordinates of the sequence in a bi-dimensional space and the distance between two binary sequences $\left(x_{i}, x_{\ell}\right)$ is the Euclidean distance between a couple of lexicographic indices

$$
r\left(x_{i}, x_{\ell}\right)=\sqrt{\left(d^{\prime}\left(x_{i}\right)-d^{\prime}\left(x_{\ell}\right)\right)^{2}+\left(d^{\prime \prime}\left(x_{i}\right)-d^{\prime \prime}\left(x_{\ell}\right)\right)^{2}} .
$$

\footnotetext{
${ }^{2}$ Duration and timing are two of the three aspects identified by Studer and Ritschard (2016) as mattering in sequence comparison. Here, we do not pay attention to the third one, sequencing, which is not a concern for studying (de)synchronization.
} 
Passing from a binary sequence to a multinomial sequence is easy. Just as a qualitative variable of $m$ modality can be represented by $m$ dummy variables, so a multinomial sequence of alphabet $Q$ can be represented by $|Q|$ binary sequences $x_{q}$ with values $0-1$. For example, the sequence $x=[123321]$ and alphabet $Q=\{1,2,3\}$ can be represented by the following three binary sequences $x_{1}=$ [100001]; $x_{2}=$ [010010]; $x_{3}=$ [001100]. To each of these binary sequences it is possible to apply the lexicographic index and compute the coordinates $\left\{d_{q}^{\prime}\left(x_{q}\right) ; d_{q}^{\prime \prime}\left(x_{q}\right)\right\}$. The multinomial sequence $x$ is therefore described by a vector of real numbers. The distance between two multinomial sequences $\left(x_{i}, x_{\ell}\right)$ is the Euclidean distance between their transformations $\left\{d^{\prime}\left(x_{i q}\right) ; d^{\prime \prime}\left(x_{i q}\right)\right\}$ and $\left\{d^{\prime}\left(x_{\ell q}\right) ; d^{\prime \prime}\left(x_{\ell q}\right)\right\}$. Formally, it is:

$$
r^{\prime}\left(x_{i}, x_{\ell}\right)=\sqrt{\sum_{q=1}^{|Q|}\left(d^{\prime}\left(x_{i q}\right)-d^{\prime}\left(x_{\ell q}\right)\right)^{2}+\left(d^{\prime \prime}\left(x_{i q}\right)-d^{\prime \prime}\left(x_{\ell q}\right)\right)^{2}} .
$$

We conclude this section of the paper by briefly discussing the index just presented. Firstly, it is not a comparison between the sequences that defines their distance. The index has a known beginning and end; each point is univocal and identifies one and only one combination of states in sequence. Two sequences which differ in the position of only one element will have different positions. From every point one can retrace the exact sequence that has produced it. A second characteristic of the index concerns its output. Each value of the index, in fact, can be conceived as a coordinate in the space of the multinomial sequence. This characteristic enables the researcher to adopt different methods to calculate the distance, but also to define forms of space other than Euclidean. Furthermore, the third characteristic is the natural way in which to handle multichannel sequences.

\section{The Data, Their Organization and the Coding of the Activities in a Multichannel Approach}

The goal of our analysis was to discover how 873 Italian dual-earner couples organized their daily activities during a typical work day from Monday to Friday.We used data from the Italian Time Use Survey 2008 (Istat 2011). We considered timeuse diaries of dual-earner couples' activities (His and Her) from 7.00 to 22.00. ${ }^{3}$ Each daily activity was observed every $10 \mathrm{~min}$, and the data files for the sequence analysis consisted of 873 pairs of sequences, one for Him and one for Her, with

\footnotetext{
${ }^{3}$ Excluded from the sample were: (a) couples living with other couples (parents or others); (b) couples that filled in the questionnaire on different days, or during the weekend; (c) couples with incomplete information by one or both of the spouses; and, (d) couples in which his or her age was over 65.
} 
a total of 90 points in time. Each couples of rows of this file corresponded to a cohabitation, while each variable corresponded to $10 \mathrm{~min}$ of observation and each cell of the row/column intersection stated the activities of Him or Her at time $t$.

In order to simplify the analysis, six different groups of activity were considered: Sleep; personal care-i.e. having a shower, eating, etc. (P.Care); paid work (Work); moving - any kind (Move); unpaid work-i.e. housework, child care, repair, etc. (H.Care); free time and other activities with or without others (F.Time).

Having defined the six daily macro-activities, the next step was to establish how to codify the daily activities of Him and Her in the couple. In this case, His activities and Her activities interact in time to give rise to the couple's daily activities. Taken individually, each of these two sequences takes the form of a series of mutually exclusive episodes. The problem is therefore how to codify two interacting sequences composed of a plurality of mutually exclusive events. To date, all the solutions proposed have been based on the generation of events combinations (Pollock 2007; Gauthier et al. 2010; Aisenbrey and Fasang 2017): that is, on the construction of a single sequence that combines the states of Him and Her.

This operation has several consequences. Firstly, as Abbott pointed out, using combinations of events requires one to pay "... the price of losing all information about the temporal 'shape' of events - their duration and their intensity in terms of producing occurrence-in short their time horizon" (Abbott 1990, p. 146). Secondly, there is the risk that distinct time-use patterns will be tied together, although the order of causality may be bi-directional.

There are various reasons to believe that daily activities of Him and Her cannot be reduced to a simple combination of states. Internally, moreover, each sequence consists of states regulated by their own mechanisms which operate differently in defining the timing and duration of each individual episode. For instance, consider the mechanisms that underlie the regulation of the states of free time and housework. In the former case, it is the working time that mainly regulates the time spent on these two activities; in the latter, we should expect a stronger interaction between gender roles.

It is therefore possible to hypothesize that the sequences of Him and Herand the states of which they are composed-have their own underlying generative mechanisms which establish the timing and duration of episodes. These generative mechanisms work independently of each other and interact in time: they stand in a coexistence relationship. Finally, the couple's daily activities are the result of a complex process of co-action between two sequences, that of Him and that of Her, regulated by different generative mechanisms resulting from the co-action between different states. Consequently, reducing everything to a combination of events means loss of a large part of information about the temporal 'shape' of events.

A couple's daily activities, or more correctly the couple sequences analyzed here, are therefore configured by the co-action of two multinomial sequences composed of mutually exclusive episodes. By extending the proposed application of the Lexicographical Index (see Sect. 2) to this case-study, 12 binary sequences can be defined, six for His states and six for Her states, each one of length $t=90$, that is, the overall number of points of observation. The couple sequence is defined as a 
point in a 24-dimension space whose coordinates are the 24 lexicographic indexes defining the respective sequences of Him and Her. The distance between two couple sequences is given by the Euclidean distance between the two points of the two sequences in the 24-dimension space.

The coordinates defined for all 873 couples were analyzed using a $k$-means cluster algorithm. ${ }^{4}$ The joint exam of the scree plot (Makles 2012) of the kink in the curve generated from the within sum of squares (WSS), the $\eta^{2}$ coefficient $(0.43)$ and the proportional reduction of error, suggests that seven is the optimal number of groups drawn from a set of 20 cluster solutions with random starting points.

\section{From 7.00 to 22.00: A Typical Working Day of a Dual-Earner Couple in Italy}

It is not news that the everyday life of a dual-earner couple is complex. It involves a long and difficult schedule of: waking up, having a shower, breakfast, taking the car-bus-train, going to work, beginning work, lunch, resuming work, coming back home, then housework and family/child care for Her, relaxation for Him, dinner, and at the end of the day, before they go to sleep, some leisure activity. Overall (Fig. 1), this was also the typical daily routine followed by our 873 Italian dual-earner couples from 7.00 to 22.00 . Looking at the most frequent activity combinations in the morning, at $7.00,75.0 \%$ of couples were involved in personal care or going to work. From 8:00am to 6:00pm all the couples were at work. ${ }^{5}$ At 6:00pm, the couples started to be desynchronized: She was engaged in housework/children care; meanwhile He continued to work until 7.00pm. From 7.00pm to 7.30pm, He had some free-time activities, while She continued her housework activity. Finally, together, they had dinner and engaged in free-time activities.

Differences in the spouses' daily time-budgets for each activity (Table 1) also confirm a well-known finding on the unequal gender division of work-family activities (Gershuny and Robinson 1988; Raley et al. 2012; Craig et al. 2014). For instance, on average, She spends 2 and a half hours more than her partner on housework and childcare, while He spends $1 \mathrm{~h}$ and a half more than his partner on paid work.

However, the timing of this daily organization changes when we move from general into the seven clusters. In this case, there emerges a more composite picture of daily life, where "multiple equilibria" (Esping-Andersen et al. 2013) of time allocation during a typical workday and (de)synchronization strategies jointly explain the dual-earner couple's patterns of time use. The average time activities (Table 1) show a clear difference in the time spent on each activity by Him and Her within partners and among clusters.

\footnotetext{
${ }^{4}$ Our distance measure between sequences could as well be used for clustering with the propertybased and fuzzy methods addressed by Studer (2018) in this bundle.

${ }^{5}$ The absence of a break for lunch does not mean that spouses do not eat; only that, overall, there is not a common time interval for lunch due to the different work schedules.
} 


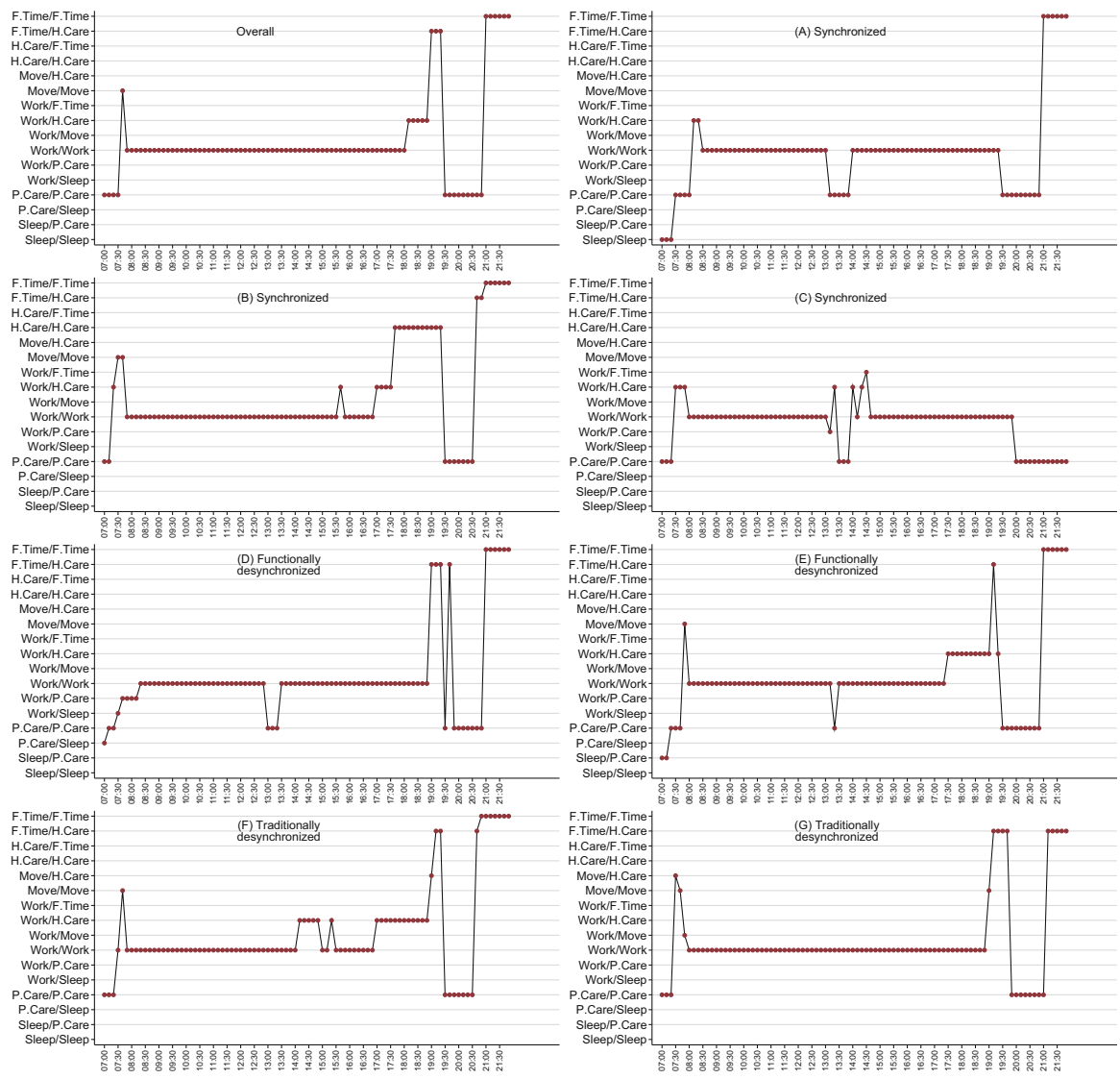

Fig. 1 Modal sequence graphs of the (de)synchronized patterns of His/Her activities (labels show Him activity/Her activity in that order)

Moreover, on shifting the focus to the schedules of each activity, the modal sequence graphs ${ }^{6}$ (Fig. 1), give us a clearer picture of how the strategies of dualearner time-use change over time in a typical workday. Both within the spouses and among the clusters the differences in time-use (Fig. 1) mainly occur in the second part of the workday. Until noon the couple's everyday lives are quite "synchronized". Him and Her show differences in the afternoon, when fewer women than men are at work and when the women shift their activities from paid to unpaid work (housework, child care, etc.). In other words, gender inequalities in the workfamily balance are generally set in the afternoon.

\footnotetext{
${ }^{6}$ For each cluster and for each point-in-time, the most frequent activities combination was identified. On this criterion, only 16 of all the 36 (six for each spouse) possible combinations were found to be frequently performed by the couples, suggesting a certain routine by couples in everyday life.
} 
Table 1 Mean time (in hours:minutes) spent on each activity, by cluster

\begin{tabular}{cccccccccccccc}
\hline & \multicolumn{3}{c}{ Sleep } & \multicolumn{3}{c}{ Personal Care } & \multicolumn{3}{c}{ Paid Work } & \multicolumn{3}{c}{ Unpaid Work } & \multicolumn{3}{c}{ Moving } & \multicolumn{3}{c}{ Free Time } \\
Cluster & M & W & M & W & M & W & M & W & M & W & M & W & $N$ \\
\hline (A) & $01: 04$ & $00: 44$ & $02: 02$ & $01: 58$ & $07: 27$ & $06: 09$ & $01: 10$ & $03: 27$ & $01: 17$ & $01: 19$ & $02: 00$ & $01: 24$ & 108 \\
(B) & $00: 04$ & $00: 03$ & $01: 50$ & $01: 49$ & $07: 26$ & $06: 30$ & $01: 51$ & $03: 51$ & $01: 23$ & $01: 18$ & $02: 27$ & $01: 28$ & 158 \\
(C) & $00: 14$ & $00: 11$ & $02: 06$ & $02: 01$ & $07: 58$ & $06: 16$ & $01: 13$ & $03: 30$ & $01: 42$ & $01: 26$ & $01: 47$ & $01: 36$ & 67 \\
(D) & $00: 03$ & $00: 38$ & $02: 09$ & $02: 01$ & $08: 38$ & $06: 07$ & $00: 50$ & $03: 35$ & $01: 18$ & $01: 17$ & $02: 02$ & $01: 23$ & 99 \\
(E) & $00: 51$ & $00: 02$ & $02: 10$ & $01: 53$ & $07: 46$ & $06: 58$ & $01: 05$ & $03: 25$ & $01: 14$ & $01: 24$ & $01: 55$ & $01: 18$ & 129 \\
(F) & $00: 08$ & $00: 08$ & $02: 08$ & $01: 51$ & $08: 45$ & $06: 07$ & $00: 30$ & $03: 59$ & $01: 24$ & $01: 18$ & $02: 05$ & $01: 37$ & 179 \\
(G) & $00: 01$ & $00: 00$ & $02: 02$ & $01: 50$ & $08: 32$ & $07: 28$ & $01: 08$ & $03: 15$ & $01: 35$ & $01: 38$ & $01: 42$ & $00: 49$ & 133 \\
Total & $00: 19$ & $00: 13$ & $02: 03$ & $01: 54$ & $08: 06$ & $06: 32$ & $01: 06$ & $03: 37$ & $01: 24$ & $01: 23$ & $02: 02$ & $01: 22$ & 873 \\
$F$ test & $31.5^{* *}$ & $42.5^{* *}$ & $3.6^{* *}$ & 1.6 & $12.9^{* *}$ & $8.6^{* *}$ & $18.9^{* *}$ & $2.8^{*}$ & $3.1 * *$ & $3.9 * *$ & $4.3^{* *}$ & $6.9^{* *}$ \\
\hline
\end{tabular}

Note: $* p<0.1, * * p<0.05, * * * p<0.01$

Hence, the preliminary results seem to suggest that, on the one hand, gender specializations in different activities can assume different meanings when contextualized in the whole day and, on the other hand, that the partners' daily life seems to develop with socially shared, recognized, and identifiable patterns of combined time use. This insight raises two further questions. The first is how these patterns result from a complex process of adaptation to both work-social-family constraints and individual needs. The second question concerns how the daily times are combined by spouses, and how their performed combinations are random instead of being regulated by common generative mechanisms.

In order to investigate the complex process of adaptation of dual-earner couples' daily time organization, we ran a multinomial logistic regression model to verify if such patterns resulted from working-social-familial and individual constraints (Table 2). For this analysis, we used information about the couple's educational qualifications, social class, economic sector, and the presence of children. ${ }^{7}$

A joint reading of the modal multichannel sequence graphs (Fig. 1), the multinomial logistic regression parameters (Table 2) and the margins estimated probability (Table 3) quite clearly shows what are the (de)synchronization strategies adopted by couples and what may be the hidden generative mechanisms (Hallberg 2003). We highlight the importance of the presence of children, work sector and the educational level in explaining the cluster differences (Table 2).

Three different forms of time-use organization are highlighted by the graphs (Fig. 1). The first is characterized by a general synchronization of the spouses'

\footnotetext{
${ }^{7}$ Educational qualifications were classified as: (1) compulsory level-elementary school certificate (including no educational qualifications) and lower-secondary school certificate (including 2-to3 year vocational certificates); (2) upper-secondary school diploma (including post-secondary diplomas); and, (3) university degree (including postgraduate qualifications). Social class was classified according to the EGP scale: (I+II) Service class; professionals, administrators, and managers; (IIIa) Routine non manual workers; (IVabc) Petty bourgeoisie; Farmers; (VI+VIIab) Skilled and non-skilled workers; Agricultural Labourers. The economic sector (agriculture and industry, private services and public services) of the couple was the combination of the main job sector of Him and Her. The couple's educational level (and social class) is defined as the highest educational level (social class position) between the spouses.
} 
Table 2 Multinomial logistic regression on the seven clusters by presence of children and sector, level of education and social class of couple. (Jackknife replication). Reference cluster (A)

\begin{tabular}{|c|c|c|c|c|c|c|}
\hline & B & $\mathrm{C}$ & $\mathrm{D}$ & $E$ & $\mathrm{~F}$ & G \\
\hline \multicolumn{7}{|c|}{ Children (ref. No child) } \\
\hline Children 0-14 & $0.72 * *$ & 0.15 & 0.13 & $0.66^{*}$ & 0.52 & $0.92 * * *$ \\
\hline Children 14+ & $0.84 * *$ & -0.17 & 0.52 & 0.54 & $0.82 * *$ & $0.93 * *$ \\
\hline \multicolumn{7}{|c|}{ Sector (ref. both Industry) } \\
\hline Both priv. services & $-2.22 * * *$ & $-1.47 * *$ & $-1.62 * *$ & $-1.61 * *$ & $-2.58 * * *$ & $-1.89 * * *$ \\
\hline Both pub. services & -0.38 & -0.39 & $-1.60 *$ & -0.92 & -1.23 & $-1.45^{*}$ \\
\hline $\begin{array}{l}\text { He industry \& } \\
\text { She pub. services }\end{array}$ & -0.84 & -0.70 & -1.08 & -1.25 & -1.12 & $-1.78 * *$ \\
\hline $\begin{array}{l}\text { He priv. services \& } \\
\text { She pub. services }\end{array}$ & $-1.39 *$ & -1.16 & -0.66 & -0.45 & -1.10 & $-1.44 *$ \\
\hline Others & $-1.24 *$ & $-1.23^{*}$ & -0.99 & -0.85 & $-1.58 * *$ & -0.97 \\
\hline \multicolumn{7}{|c|}{ Education (ref. University) } \\
\hline $\begin{array}{l}\text { Upper-secondary } \\
\text { school diploma }\end{array}$ & $0.73 * *$ & $1.11 * *$ & $0.72 *$ & 0.18 & $0.77 * *$ & $0.88 * *$ \\
\hline Compulsory & 0.24 & 0.56 & 0.54 & -0.04 & $0.75^{*}$ & $0.88 *$ \\
\hline \multicolumn{7}{|l|}{ Social class (ref. I+II) } \\
\hline IIIa & $1.29 * *$ & $-0.99 *$ & 0.03 & 0.65 & 0.36 & 0.67 \\
\hline IVabc & 0.90 & -0.62 & -0.59 & 0.71 & 0.25 & -0.47 \\
\hline VI+VIIab & $1.93 * *$ & -0.23 & 0.20 & $1.25^{* *}$ & 0.64 & -0.04 \\
\hline Constant & -0.73 & 0.37 & 0.43 & -0.10 & 0.59 & 0.00 \\
\hline
\end{tabular}

Note: $* p<0.1, * * p<0.05, * * * p<0.01$; Pseudo $R^{2}=0.05$

different activities during the day. This maximally "egalitarian" (Esping-Andersen et al. 2013) gender participation in unpaid work seems able to preserve the free time of the spouses. Couples in clusters (A) and (B) are associated with the highest synchronization levels.

These dual-earner couples are characterized by a tertiary educational level for couples in cluster (A) and a secondary educational level for those in cluster (B) (Table 3). Thus, a low educational level seems to be an obstacle to an egalitarian strategy of synchronization.

What distinguishes the two clusters is the presence of children (Table 2), which increases the probability of being a member of cluster (B), while the couples in cluster (A) are more likely to be without a child. There are also differences of occupational sector and class between the couples in clusters (A) and (B). Couples in cluster (A) work in the private services sector, while those in cluster (B) are mainly employed in the public services sector. At the same time, couples in cluster (B) are mainly employees (IIIa or VI + VIIab), while in cluster (A) they are more likely to be self-employed (I + II or IVabc).

This particular combination of characteristics-and constraints-creates synchronized couples' patterns (Fig. 1). However, there are some substantive differences. In cluster (B), the spouses seem to have breakfast together before going 
Table 3 Predictive margins probability (in percentage) on the seven clusters by presence of children, sector, level of education and social class of couple. Marginal effects at reference profile*

\begin{tabular}{|c|c|c|c|c|c|c|c|}
\hline & A & B & $\mathrm{C}$ & D & E & $\mathrm{F}$ & $\mathrm{G}$ \\
\hline \multicolumn{8}{|l|}{ Children (ref. No child) } \\
\hline Children 0-14 & 7.9 & 7.8 & 13.2 & 13.8 & 13.7 & 23.9 & 19.8 \\
\hline Children 14+ & 7.1 & 7.8 & 8.6 & 18.4 & 11.0 & 29.2 & 18.0 \\
\hline \multicolumn{8}{|l|}{ Sector (ref. both Industry) } \\
\hline Both priv. services & 46.3 & 2.4 & 15.4 & 14.1 & 8.4 & 6.4 & 7.0 \\
\hline Both pub. services & 26.7 & 8.8 & 26.1 & 8.3 & 9.6 & 14.2 & 6.3 \\
\hline He industry \& She pub. services & 28.9 & 6.0 & 20.7 & 15.1 & 7.5 & 17 & 4.9 \\
\hline He priv. services \& She pub. services & 26.4 & 3.2 & 11.9 & 21.1 & 15.2 & 15.9 & 6.3 \\
\hline Others & 30.6 & 4.3 & 12.9 & 17.5 & 11.8 & 11.4 & 11.6 \\
\hline \multicolumn{8}{|l|}{ Education (ref. University) } \\
\hline Upper-secondary school diploma & 5.9 & 5.8 & 25.8 & 18.7 & 6.4 & 23.1 & 14.3 \\
\hline Compulsory & 7.2 & 4.4 & 18.2 & 19.1 & 6.2 & 27.5 & 17.4 \\
\hline \multicolumn{8}{|l|}{ Social class (ref. I+ II) } \\
\hline IIIa & 9.0 & 15.6 & 4.8 & 14.2 & 15.5 & 23.4 & 17.5 \\
\hline IVabc & 11.6 & 13.7 & 9.1 & 9.9 & 21.4 & 27.1 & 7.3 \\
\hline $\mathrm{VI}+\mathrm{VII} a b$ & 6.7 & 22.2 & 7.7 & 12.6 & 21.3 & 23.0 & 6.5 \\
\hline Reference profile $^{\mathrm{a}}$ & 12.2 & 5.9 & 17.7 & 18.8 & 11.0 & 22.1 & 12.3 \\
\hline
\end{tabular}

${ }^{a}$ Reference profile: Children (No child), Sector (both Industry), Education (University), Social class $(\mathrm{I}+\mathrm{II})$

to work and starting it synchronically. They both stop working quite early in the afternoon, favored probably by their kind of job and the economic sector in which they are employed. At 17:00 She is already at home, while He comes back at 17:40. Thereafter, both the spouses spend the rest of the day at home, doing housework and childcare before having dinner together and, finally, enjoying most of their free time synchronically. The only second part of the day in which they are not synchronized is the one immediately after dinner, when She postpones her free time for $20 \mathrm{~min}$ due to housework (Fig. 1).

In cluster (A) the absence of children and the type of work (self-employment in the private services sector) would seem to explain why the couples start their day in a manner differently from the others (Fig. 1). Both the spouses wake up together, and later than the couples in other clusters. They also have breakfast at the same time. Then He leaves the house while She quickly tides up before going to work. Job commitments fill equally most of their daily time. Moreover, their lunch and dinners are synchronized. Finally, the extent of their job commitments and the parallel absence of children seem to pull the spouses in cluster (A) directly to free and leisure time. ${ }^{8}$

\footnotetext{
${ }^{8}$ The absence of housework does not mean that spouses do not perform any housework. Simply, they are more likely to do it in a non-regular way, during brief and scattered moments of spare time.
} 
Cluster (C) falls - although not completely — within the synchronized time-use patterns (Fig. 1). Couples in this cluster have some features in common with those of cluster (A). In particular, like dual-earner couples (A), those in cluster (C) are more likely to be childless. They also are mainly members of the upper class (I+II) (Table 3).

Cluster (C) has some characteristics in common with clusters (A) and (B) also in terms of daily time organization, even if its pattern ends with a longer tail of synchronized personal care: spouses may still be having dinner together at the end of the observation (22:00). However, what really makes cluster (C) unique is the time organization around lunch. While for cluster (B), there is no specific time for lunch, and for cluster (A) the time interval for lunch is well defined between two work 'segments', for cluster (C) the break from work is longer for Her. Moreover, around a certain synchronized lunch-time, there is a certain desynchronization due to His work commitments and Her housework tasks. Finally, before going back to work, She is even able to spend a short time relaxing. Here, the sequence of activity combinations around lunch is much more chaotic, fragmented and desynchronized compared with the clusters (A) and (B). However, except for this desynchronized part of the day, probably due to different work commitments, the rest of the day is mainly synchronized.

Alongside the synchronized patterns other desynchronized daily time-use patterns emerge. These strategies of desynchronization seem to be specialized into two forms, on the basis of the kind of tasks sequentially performed and combined by the two spouses during the day.

The first kind of strategy is called functionally desynchronized. Here, gender differences in activities-in-time appear to be an adaptation to structural desynchronization (Nock and Kingston 1984) of His and Her working schedules. The difference in work duration between men and women appears to produce a counterbalancing force by which—at the end of the work day-She 'compensates' the different spread of paid-work commitments of Him with unpaid work, in a quite calibrated way that preserves the free time of both the spouses. The gender division of work-family activities is "unstable" (Esping-Andersen et al. 2013), mostly due to "structural constraints" of the partners" working schedules.

Couples in clusters (D) and (E) are associated with the clearest functionally desynchronized patterns. For both clusters, Her working schedule is shifted forward in the afternoon (Fig. 1) and in most cases at least one spouse of these dual-earner couples is employed in the public sector. The most important differences between these couples is that (D) do not have a child while (E) do so (Table 2).

In cluster (D), He starts work much earlier than Her. On the other hand, She spends more time on personal care before going out to work. The probable absence of children may be helpful in this regard. At the end of the workday, these spouses come back home later and synchronically. Once at home, they desynchronize

Moreover, they may not necessarily do the housework every day, maybe postponing the chores to the weekend. 
themselves again (Fig. 1) and while He takes a break to relax, She does some housework. It seems that there is some sort of compensation of daily time activities: He starts work much earlier than Her in the morning, and the gendered housework at the end of the day seems useful in establishing the balance, before dinner. Finally, they both eat and relax together (Fig. 1).

In the time-use pattern (E), She wakes up a little before Him, probably because of the young children's demands. They have breakfast together before going to work, and they start working synchronically. In the afternoon, She leaves the workplace much earlier than Him, perhaps in order to devote herself again to childcare and housework. After His return from work, they eat together, before spending synchronous free time. Again, the clear non-cooperation of Him in the household tasks may be due to the evident spread of work commitments during the whole day.

The second desynchronizations strategy is what we call traditional. Here, the couple's distribution of activities during the day does not seem to follow any compensatory mechanism. The overall desynchronization seems to be weakly linked to the "structure" of the spouses' work commitments (Nock and Kingston 1984). Conversely, it appears to be an outcome of a more "traditional" gender attitude to the work-family balance. Here, the result is a marked overload in paid/unpaid work for women (Mattingly and Blanchi 2003), with stronger evidence of the gendered leisure gap (Beblo and Robledo 2008).

Couples in clusters (F) and (G) are characterized by the presence of younger children, a low level of education, mainly compulsory level, and are mainly employed in the industrial sector. There are some differences in job features: couples in cluster $(\mathrm{G})$ are mainly members of the white collar middle class (IIIa), while those in cluster $(\mathrm{F})$ are mainly members of the petty bourgeoisie (IVabc). Moreover, cluster $(\mathrm{G})$ shows a relatively high presence of couples where He works in the industrial sector and She in the public sector or He does so in the private sector and She in the public sector.

The time-use pattern of cluster (F) is apparently similar to that of cluster (E). In fact, She comes back home before Him and deals with domestic chores. However, compared with cluster (E) we note a greater extension of Her household commitments, from the early afternoon until the evening, when He has already finished his workhours. Thus, on one hand the desynchronization seems functional for the long time spent by Him at work; on the other hand, this couple's timeuse pattern does not show any cooperative or compensatory forms of time-use organization between the spouses (Fig. 1).

Last but not least, cluster $(\mathrm{G})$ is certainly the maximum expression of the traditional desynchronization. The time-use pattern $(\mathrm{G})$ describes a couple in which everything is on Her shoulders. The delay of the exit from home is followed by a long journey to work. Then, she continues to work until the late afternoon. Finally, when both the spouses return home, He takes a break and rests, while She continues to do housework and child care. The only synchronized moment in the final part of this couple's pattern is when they have dinner. Among all the time-use patterns, this is certainly the one with the highest level of gender inequality in regard to the daily work-family balance challenge (Fig. 1). 


\section{Conclusions}

In the introduction of this paper, we pointed out the importance of adopting a multichannel sequence analysis approach to gain better understanding of the complexity of the work-family balance through holistic study of dual-earner couples' daily time use as an overall pattern. At the end of this paper, it is evident that the sequence analysis of time use diaries provides a rather clear and meaningful representation of the main patterns of the everyday organization of Italian dual-earner couples. The analysis shows the clear co-action of multiple generative mechanisms that give shape and relevance to each of seven patterns and define different forms of (de)synchronization in the everyday-life organization of both individuals and couples.

These patterns are attributable to three different strategies for organization of daily activities, and three types of equilibria (Esping-Andersen et al. 2013) within the family. In fact, these patterns describe three sets of work-family equilibrium strategies performed by dual-earner couples, with different expected levels of desirability. The first defines the synchronization strategies (clusters A, B and C). Hence, the housework division by gender is "egalitarian" because both partners participate in the housework and are able to share most of the free time available. The second defines the functional desynchronization strategies (clusters D and E). The division of housework by gender is "unstable" (Esping-Andersen et al. 2013) mostly because of "structural constraints" of the partners' work schedules (Nock and Kingston 1984). Nevertheless, the behavior of Him and Her reflects a collaborative complementarity which still tends to preserve the free time of both. The third pattern defines the traditional desynchronization strategies (clusters $\mathrm{F}$ and G). Partners are characterized by an unequal division of housework. They exhibit the classic features of a "traditional" equilibrium where the woman has heavy overexposure to home/child care tasks and limited free time availability (Mattingly and Blanchi 2003; Beblo and Robledo 2008).

The close relations with certain household features (the presence of children and the couple's level of education, social class and job sector) support the contention that such behaviors and patterns result, on the one hand, from the internal bargaining among each couple conditioned by the cultural-economic characteristics of the partners themselves, and, on the other, by external social constraints. ${ }^{9}$

The time-use patterns result from the complex co-action among individual, family and social factors whose combination defines the relevance and the shape of patterns. The time balance within His and Her activities, as well as its configuration across the day, is not random; rather, it changes according to multiple latent factors.

Dual-earner couples package their daily life mainly in accordance with their work and its schedules, and therefore mainly the type of job and the economic sector (Hamermesh 2002; Warren 2003; Lesnard 2008). Moreover, the analyses

\footnotetext{
${ }^{9}$ The solutions of these particular couples in daily scheduling affected the spouses' level of satisfaction as an outcome of daily life quality. For details see Bison and Scalcon (2016).
} 
show that this time packaging changes in relation to the presence of children. We observed that the presence of children (especially young ones) introduces elements of desynchronization and specialization within the couples. The impact of young children, however, may differ according to both the couples' work schedules and their gendered attitudes to work-family activities. According to such a view, the last factor is the couples' level of education. We can assume it as a proxy for the predisposition towards egalitarian gender attitudes (Hakim 2003; Oláh et al. 2014). Not by chance, the most "egalitarian" strategies of synchronization are performed by high-educated couples, while the most "traditional" strategies of not functional desynchronization are performed by couples with a low level of education.

In conclusion, the presence of children, the level of education, and job characteristics are three dimensions that contribute to defining the patterns of couples' daily activities, already constrained by several social rhythms (i.e. school hours; lunch and dinner time; shop opening hours; etc.).

Acknowledgements The authors warmly thank the anonymous reviewers for their constructive comments.

\section{References}

Abbott, A. (1990). A primer on sequence methods. Organization Science, 1(4), 375-392.

Abbott, A., \& Tsay, A. (2000). Sequence analysis and optimal matching methods in sociology: Review and prospect. Sociological Methods \& Research, 29(1), 3-33.

Aisenbrey, S., \& Fasang, A. (2017). The interplay of work and family trajectories over the life course: Germany and the united states in comparison. American Journal of Sociology, 122(5), 1448-1484.

Beblo, M., \& Robledo, J. R. (2008). The wage gap and the leisure gap for double-earner couples. Journal of Population Economics, 21(2), 281-304.

Becker, G. S. (1964). Human capital national bureau of economic research. New York: National Bureau of Economic Research.

Berk, S. (1985). The gender factory: The apportionment of work in American households. Boston: Springer US.

Bison, I. (2009). Om matters: The interaction effects between indel and substitution costs. Methodological Innovations Online, 4(2), 53-67.

Bison, I. (2011). Lexicographic index: A new measurement of resemblance among sequences. In A. Bryman (Ed.), The SAGE handbook of innovation in social research methods (p. 422). London/Thousand Oaks: Sage.

Bison, I., \& Scalcon, A. (2016). From 07.00 to 22.00: A dual-earner typical day in Italy. Old questions and new evidences from social sequence analysis. In G. Ritschard \& M. Studer (Eds.), Proceedings of the International Conference on Sequence Analysis and Related Methods, Lausanne, June 8-10 (pp. 35-71).

Chenu, A., \& Robinson, J. P. (2002). Synchonicity in the work schedules of working couples. Monthly Labor Review, 125(4), 55-63.

Coverman, S. (1985). Explaining husbands' participation in domestic labor. The Sociological Quarterly, 26(1), 81-97.

Craig, L., Powell, A., \& Smyth, C. (2014). Towards intensive parenting? Changes in the composition and determinants of mothers' and fathers' time with children 1992-2006. The British Journal of Sociology, 65(3), 555-579. 
Dijkstra, W., \& Taris, T. (1995). Measuring the agreement between sequences. Sociological Methods \& Research, 24(2), 214-231.

Elzinga, C. H. (2003). Sequence similarity. Sociological Methods \& Research, 32(1), 3-29.

Esping-Andersen, G., Boertien, D., Bonke, J., \& Gracia, P. (2013). Couple specialization in multiple equilibria. European Sociological Review, 29(6), 1280-1294.

Gauthier, J.-A., Widmer, E. D., Bucher, P., \& Notredame, C. (2010). Multichannel sequence analysis applied to social science data. Sociological Methodology, 40(1), 1-38.

Gershuny, J., \& Robinson, J. P. (1988). Historical changes in the household division of labor. Demography, 25(4), 537-552.

Hagerstrand, T. (1982). Diorama, path and project. Tijdschrift voor economische en sociale geografie, 73(6), 323-339.

Hakim, C. (2003). A new approach to explaining fertility patterns: Preference theory. Population and Development Review, 29(3), 349-374.

Hallberg, D. (2003). Synchronous leisure, jointness and household labor supply, Labour Economics, 10(2), 185-203, ISSN 0927-5371 https://www.sciencedirect.com/science/article/ abs/pii/S092753710300006X

Hamermesh, D. S. (2002). Timing, togetherness and time windfalls. Journal of Population Economics, 15(4), 601-623.

Hellgren, M. (2014). Extracting more knowledge from time diaries? Social Indicators Research, 119(3), 1517-1534.

Istat (2011). Indagine multiscopo sulle famiglie - Uso del tempo anno 2008-2009. manuale utente. Technical report, Istat.

Lesnard, L. (2008). Off-scheduling within dual-earner couples: An unequal and negative externality for family time. American Journal of Sociology, 114(2), 447-490.

Makles, A. (2012). Stata tip 110: How to get the optimal k-means cluster solution. Stata Journal: StataCorp LP, 12(2), 347-351.

Manser, M., \& Brown, M. (1980). Marriage and household decision-making: A bargaining analysis. International Economic Review, 21(1), 31-44.

Mansour, H., \& McKinnish, T. (2014). Couples' time together: Complementarities in production versus complementarities in consumption. Journal of Population Economics, 27(4), 11271144.

Mattingly, M. J., \& Blanchi, S. M. (2003). Gender differences in the quantity and quality of free time: The U.S. experience*. Social Forces, 81(3), 999-1030.

Naldini, M., \& Saraceno, C. (2011). Conciliare famiglia e lavoro: vecchi e nuovi patti tra sessi e generazioni. Il Mulino, Bologna.

Nock, S. L., \& Kingston, P. W. (1984). The family work day. Journal of Marriage and Family, 46(2), 333-343.

Oláh, L. S., Richter, R., \& Kotowska, I. E. (2014). State-of-the-art report. The new roles of men and women and implications for families and societies. Families and societies. FamilesAndSocieties Working Paper Series 11, Stockholm University.

Pollock, G. (2007). Holistic trajectories: A study of combined employment, housing and family careers by using multiple-sequence analysis. Journal of the Royal Statistical Society: Series A (Statistics in Society), 170(1), 167-183.

Presser, H. B. (1994). Employment schedules among dual-earner spouses and the division of household labor by gender. American Sociological Review, 59(3), 348-364.

Raley, S., Bianchi, S. M., \& Wang, W. (2012). When do fathers care? Mothers' economic contribution and fathers' involvement in child care. American Journal of Sociology, 117(5), $1422-1459$.

Saraceno, C. (2012). Coppie e famiglie. Feltrinelli Editore.

Studer, M. (2018). Divisive property-based and fuzzy clustering for sequence analysis. In G. Ritschard \& M. Studer (Eds.), Sequence analysis and related approaches: Innovative methods and applications. Cham: Springer (this volume). 
Studer, M., \& Ritschard, G. (2016). What matters in differences between life trajectories: A comparative review of sequence dissimilarity measures. Journal of the Royal Statistical Society, Series A, 179(2), 481-511.

Warren, T. (2003). Classand gender-based working time? time poverty and the division of domestic labour. Sociology, 37(4), 733-752.

West, C., \& Zimmerman, D. H. (1987). Doing gender. Gender \& Society, 1(2), 125-151.

Wu, L. L. (2000). Some comments on "sequence analysis and optimal matching methods in sociology: Review and prospect”I. Sociological Methods \& Research, 29(1), 41-64.

Open Access This chapter is licensed under the terms of the Creative Commons Attribution 4.0 International License (http://creativecommons.org/licenses/by/4.0/), which permits use, sharing, adaptation, distribution and reproduction in any medium or format, as long as you give appropriate credit to the original author(s) and the source, provide a link to the Creative Commons license and indicate if changes were made.

The images or other third party material in this chapter are included in the chapter's Creative Commons license, unless indicated otherwise in a credit line to the material. If material is not included in the chapter's Creative Commons license and your intended use is not permitted by statutory regulation or exceeds the permitted use, you will need to obtain permission directly from the copyright holder. 